\title{
"Do as we say, not as we do?" the lifestyle behaviours of hospital doctors working in Ireland: a national cross-sectional study
}

\author{
Anthony $\mathrm{O}^{\prime} \mathrm{Keeffe}^{1,2^{*}}$ (D) Blánaid Hayes $\mathrm{s}^{1,2}$ and Lucia Prihodova ${ }^{2}$
}

\begin{abstract}
Background: This study was conducted to assess the lifestyle behaviours of a national sample of hospital doctors working in Ireland. We also sought to compare the prevalence of these behaviours in doctors to the general Irish population.

Methods: This was a national cross-sectional study of a randomised sample of hospital doctors working in Irish publicly funded hospitals and residential institutions. The final cohort consisted of 1749 doctors (response rate of 55\%). All hospital specialties were represented except radiology. The following data were collected: sociodemographic data (age, sex), work grade (consultant, trainee) average hours worked over a two-week period, specialty and lifestyle behaviours (smoking, alcohol, physical activity). Lifestyle data for the general population was provided by the Healthy Ireland 2015 study.
\end{abstract}

Results: Half of participants were men (50.5\%). Just over half of the sample were consultants (54.3\%), with $45.7 \%$ being trainees. $9.3 \%$ of doctors surveyed were smokers, $88.4 \%$ consumed alcohol and $24.5 \%$ were physically inactive. Trainees were more likely to smoke and be physically inactive when compared to consultants. Smoking rates amongst doctors were lower than the general population $(9.3 \%-v-23 \%)$. Doctors were more likely to consume alcohol than the general population (88.4\% -v- 71.7\%) but less likely to engage in binge drinking on a typical drinking occasion (12.8\% -v- 39. $5 \%)$. Doctors were more compliant than the general population with minimum exercise targets ( $75.5 \%-\mathrm{v}-70.5 \%)$, but less likely to engage in health enhancing physical activity (19.1\% -v- 33\%).

Conclusions: While the prevalence of health behaviours amongst hospital doctors in Ireland compares favourably to the general population, their alcohol consumption and engagement in health enhancing physical activity suggest room for improvement. Continued health promotion and education on the importance of personal health behaviours is essential.

Keywords: Lifestyle behaviours, Doctors, Hospital, Ireland

\section{Background}

The deleterious health effects of poor lifestyle behaviours such as smoking, low physical activity and excessive alcohol intake are well established. Smoking has been shown to cause cardiovascular disease, pulmonary disease and cancer $[1,2]$ while excessive alcohol consumption has significant negative consequences for the health of individuals (e.g. cirrhosis, cancer, injuries) and society at large (e.g. drink driving) [3]. Physical inactivity is the third leading

\footnotetext{
* Correspondence: aok174@yahoo.ie

Occupational Health Department, Beaumont Hospital, Dublin, Ireland

${ }^{2}$ Research Department, Royal College of Physicians of Ireland, Dublin, Ireland
}

cause of death in the United States and contributes to the second leading cause (obesity), accounting for at least one in ten deaths [4].

Because of the impact of these behaviours, there has been an increase in research on doctors' personal lifestyle behaviours in recent years. Evidence suggests that doctors' wellbeing impacts on their ability to deliver effective care to their patients [5], and their personal lifestyle behaviours affect their preventative counselling of patients [6]. Doctors who engage in regular physical activity are more likely to counsel their patients regarding the health benefits of exercise [7]. Such counselling

(C) The Author(s). 2019 Open Access This article is distributed under the terms of the Creative Commons Attribution 4.0 International License (http://creativecommons.org/licenses/by/4.0/), which permits unrestricted use, distribution, and 
has been shown to be effective in improving the exercise habits of patients [8]. A consistent, positive relation between physicians' and their patients' preventive health practices (i.e. engaging in health screening programmes and vaccination uptake) has been demonstrated [9].

The health behaviours of doctors have also been shown to affect societal perception of the risk associated with these behaviours [10].

Although health care professionals have been shown to have lower rates of smoking and sedentary activity compared to other professions [11], there is considerable variation in the lifestyle behaviours of doctors internationally. The prevalence of smoking ranges from $2 \%$ in the US to $49 \%$ in Greece [12]. Only 29\% of primary care doctors in Singapore achieve the minimum weekly exercise target of $150 \mathrm{mins} /$ week [13], as opposed to $56.6 \%$ of primary care doctors in Northern Ireland [14].

Rates of alcohol misuse are comparable between doctors and the general population [15], and in some countries doctors engage in hazardous drinking at higher levels than the population at large [10]. In Bahrain, 98\% of primary care doctors report lifelong abstinence from alcohol [16], whereas $91 \%$ of German hospital doctors consume alcohol [17]. These disparities are reflective of cultural differences in attitudes regarding the risks, benefits and appropriateness of the individual lifestyle behaviours and therefore are difficult to generalise.

To date, there has been little research on this topic performed in the Irish context [18]. Therefore, the aim of this study was to assess the lifestyle behaviours of a wide cohort of hospital doctors working in Ireland and to compare the prevalence of health risk behaviours in this group to that of the general working age population and a cohort that was matched for age, social class and level of education.

\section{Methods}

\section{Design}

This study was a national cross-sectional prevalence survey of hospital doctors in Ireland [19].

\section{Sample}

A total sample of 3164 doctors, drawn from the registers of nine national post-graduate medical training bodies, was invited to participate in the study. The specialties represented were: anaesthetics, emergency medicine, medicine, obstetrics/gynaecology, ophthalmology, paediatrics, pathology, psychiatry and surgery. The Faculty of Radiology declined to participate. The sample included both consultants and trainees who were actively registered and working within a public hospital, public clinic or residential institution. Retirees, those practising exclusively in private practice and those working outside the jurisdiction of the Republic of Ireland were excluded from the study. In order to determine the sample size for inclusion in the postal questionnaire, the sample size for each subgroup (consultants and trainees within each specialty) within the total population was calculated for a $95 \%$ confidence interval, an acceptable margin of error of $+/-5 \%$ and an expected prevalence of $20 \%$ based on a review of the literature. This number was then doubled to allow for an estimated response rate of $50 \%$ rather than $100 \%$.

The required sample size for each training body was calculated using Raosoft [20]. When this number exceeded the actual population sample size of the training body, randomisation was not applied. Ultimately, randomisation was only necessary for four of the 18 groups: medicine (trainees and consultants), psychiatric consultants and surgical trainees. Randomisation was applied in these four groups due to the large numbers of the groups they were drawn from and to ensure that the sample used in the study adequately represented the broader cohort. Randomisation was performed using the Microsoft Excel Randomisation Function.

\section{Procedure and methods}

A self-administered questionnaire was used to assess smoking, alcohol consumption and physical activity (Additional file 1). The items in the questionnaire were largely modelled on the questionnaire used in the national survey of health and lifestyle behaviours of the Irish population SLÁN/ Healthy Ireland survey [21]. The questionnaire was distributed by post and e-mail to all invited participants in April 2014. Two reminders were sent over the following 2 months, by post and e-mail.

An extensive participant information leaflet was included with the questionnaire outlining the purpose and scope of the study (Additional file 2). The leaflet also explained that the information was being gathered anonymously to ensure confidentiality and that the response to the questionnaire was indicative of consent.

\section{Demographic and work related information}

The participants provided information on their sex, age, nationality, marital status as well as their work grade (trainee or consultant) and average hours worked per week over 2 weeks (under $40 \mathrm{~h} /$ week, 40-80 h/week, over $80 \mathrm{~h}$ /week).

\section{Smoking}

Smoking habits were assessed using two questions. Respondents were asked whether they smoke and if so, how frequently (occasionally, daily).

\section{Alcohol}

Alcohol consumption was assessed using three questions: frequency, number of standard drinks consumed on a typical drinking occasion and frequency of consuming six or more standard drinks on one occasion. Hazardous 
drinking behaviour was defined by consuming six or more standard drinks (60g of ethanol) on a single occasion, also described as "binge drinking" or "risky single occasion drinking" [22]. Hazardous drinking, not dependence, causes the majority of alcohol-related morbidity and mortality. Binge drinking accounts for almost one third of all motor vehicle deaths in the United States, as well as increasing patients' risk for homicide, suicide, assaults, and nonintentional poisoning [23].

\section{Physical activity}

The International Physical Activity Questionnaire Short Form (IPAQ-SF) was used to assess level of physical activity [24] using three categories: 1 . inactive; 2 minimally active (completing at least $150 \mathrm{~min}$ of moderate intensity exercise per week over 5 or more days); and 3 . health enhancing physical activity (HEPA; engaging in vigorous-intensity activity on at least 3 days achieving a minimum of at least 1500 MET-minutes/week (amount of energy expended carrying out physical activity)).

\section{Comparison with general population}

To allow for comparison of health behaviours with the general population we used the Healthy Ireland 2015 survey dataset (which has superseded SLÁN). This annual national survey of the health and wellbeing of the general population includes individuals age 15 and over and gathers data on lifestyle behaviours, sexual health, general health and mental health [25]. In 2015, 7539 people were interviewed in the survey. To ensure comparability of the data, two groups were selected from the total cohort for comparison with our sample: 1 . working-age general population of 25-65 years of age $(N=5209)$, and 2. population matched for age $(>25,<65)$ and social class (Class 1 and 2) and level of education (3rd level) $(N=670)$.

There was a methodological difference between the two studies. The Healthy Ireland survey was interviewer administered, whereas ours was a self-administered questionnaire.

\section{Statistical analyses}

Categorical variables were described by frequencies and percentages and between group differences were assessed with chi square tests. One-way analysis of variance (ANOVA) and independent $\mathrm{t}$-tests were used to assess differences in means between groups. Binary logistic regression was used to assess whether respondents' demographic and workplace variables were significant predictors for reporting lifestyle behaviours (smoking, binge drinking on a typical drinking occasion, physical inactivity). All dependent variables were dichotomised (presence or absence of consumption or activity). The explanatory variables included in each model were: sex, age group, work grade, nationality, marital status, mean hours worked over a 2 week period and specialty. IBM SPSS version 21 was used for the analysis of the individual cohorts (doctors and Healthy Ireland). Graphpad, an online statistical software programme, was used to test for differences between the doctor cohort and the comparator Healthy Ireland groups.

Participants who did not provide responses to specific questions were excluded from the subsequent analysis of the variable of interest.

The study protocol was approved by the Royal College of Physicians of Ireland's (RCPI) Research Ethics Committee in December 2013 (RCPI RECSAF 20).

\section{Results}

\section{Response rate}

One thousand seven hundred forty nine doctors were included in the final analysis (55\% response rate). Half of the participants were male (50.5\%), the majority held Irish nationality $(86 \%)$. Just over half of the sample were consultants (54.3\%), with $45.7 \%$ being trainees. The majority of respondents were married or cohabitating (71.1\%) (Table 1).

\section{Mean hours worked}

The mean hours worked per week over a two-week period for the sample was $57 \mathrm{~h} /$ week (SD 15.1). Males worked on average $3.4 \mathrm{~h}$ more per week than their female counterparts. Consultants worked on average $6.2 \mathrm{~h}$ less per week compared to trainees. Doctors who were single worked $5 \mathrm{~h}$ more per week than their married/cohabitating colleagues. The highest and lowest mean weekly working hours by specialty were reported in surgery $(68.6 \mathrm{~h} /$ week, SD 17.1) and psychiatry ( $47.6 \mathrm{~h} /$ week, standard deviation (SD) 12.4) respectively. The between group differences seen for age group, sex, work grade, marital status and specialty were statistically significant. There were no significant differences observed when compared by nationality (Table 1 ).

\section{Smoking}

9.4\% of the participants identified as smokers, with the majority being occasional smokers. Of the total cohort, 2.5\% smoked daily. There was a significantly higher prevalence of smokers amongst the trainee group compared to consultants $(p=0.001)$ and amongst males compared to females $(p=0.007)$. Male trainees in particular demonstrated the highest rates of smoking (16.2\%). Doctors who were single were significantly more likely to smoke compared to respondents who were married/cohabitating or divorced/separated $(p=0.000)$. The highest and lowest prevalence of smokers by specialty were observed in the emergency medicine doctors $(18.8 \%)$ and paediatricians $(6.1 \%)$ respectively (Table 2).

\section{Alcohol}

$11.4 \%$ of doctors surveyed were non-drinkers while $41.8 \%$ of the cohort reported consuming alcohol multiple times 
Table 1 Population characteristics and group differences in mean hours worked as tested by one-way ANOVA and independent ttest

\begin{tabular}{|c|c|c|}
\hline Characteristic & $\%(N)$ & Mean hours worked/week (SD) \\
\hline \multicolumn{3}{|l|}{ Age } \\
\hline$\leq 30$ & $20.1(349)$ & $61.6(13.1)^{* * *}$ \\
\hline $31-40$ & $30.4(529)$ & $57.7(15)$ \\
\hline $41-50$ & $27(469)$ & $54.7(15.7)$ \\
\hline$>50$ & $22.5(391)$ & $54.6(15.1)$ \\
\hline \multicolumn{3}{|l|}{ Sex } \\
\hline Male & $50.5(882)$ & $58.7(15.4)^{* * *}$ \\
\hline Female & $49.5(864)$ & $55.3(16.6)$ \\
\hline \multicolumn{3}{|l|}{ Nationality } \\
\hline Irish & $86(1505)$ & $57.1(15.1)$ \\
\hline Non-Irish & $14(244)$ & $56.6(15.2)$ \\
\hline \multicolumn{3}{|l|}{ Work Grade } \\
\hline Consultant (C) & $54.3(950)$ & $54.2^{* * *}$ \\
\hline Trainee $(T)$ & 45.7 (799) & 60.4 \\
\hline \multicolumn{3}{|l|}{ Sex and Work Grade } \\
\hline Male (C) & $32.9(574)$ & $56.6(14.9)^{* * *}$ \\
\hline Male (T) & $17.6(308)$ & $62.6(15.4)$ \\
\hline Female (C) & $21.5(375)$ & $50.4(14.6)^{* * *}$ \\
\hline Female (T) & $28(489)$ & $59(13.5)$ \\
\hline \multicolumn{3}{|l|}{ Marital status } \\
\hline Married or cohabitating & $71.1(1224)$ & $55.6(15.1)^{* * *}$ \\
\hline Single & $25.9(445)$ & $60.7(13.6)$ \\
\hline Divorced or separated & $3(52)$ & $56.1(18.4)$ \\
\hline \multicolumn{3}{|l|}{ Specialty } \\
\hline Anaesthetics & $14.1(247)$ & $59.3(14.4)^{* * *}$ \\
\hline Emergency & $4.9(85)$ & $53.6(11.1)$ \\
\hline Obstetrics \& Gynaecology & $6.2(108)$ & $59.7(11.5)$ \\
\hline Ophthalmology & $2(35)$ & $55.1(14.9)$ \\
\hline Paediatrics & $9.5(165)$ & $59.8(14.9)$ \\
\hline Pathology & $8(139)$ & 49.9 (13) \\
\hline Medicine & $25.4(433)$ & $56.5(12.7)$ \\
\hline Psychiatry & $16.1(281)$ & $47.6(12.4)$ \\
\hline Surgery & $13.9(243)$ & $68.6(17.1)$ \\
\hline
\end{tabular}

Between group differences: ${ }^{* * *} P$ value $\leq .001$

a week (Table 3). Of those who reported drinking alcohol, $27.5 \%$ never engage in binge drinking, while $10.1 \%$ did so at least once a week and a further 3.3\% multiple times/ week. Additionally, $12.8 \%$ reported binge drinking on a typical drinking occasion. The mean units of alcohol consumed on a typical occasion were 3.39 units (SD 2.46) (Table 3).

There was a higher reported prevalence of non-drinkers amongst the trainee and non-Irish national groups, compared to their counterparts. The rates of abstinence were almost equivalent between males and females. Married/ cohabitating doctors were more likely to abstain compared to their colleagues who were single or divorced/separated. Doctors working over $80 \mathrm{~h} /$ week had a higher rate of abstinence compared to those working under $40 \mathrm{~h} /$ week. By specialty, the highest and lowest prevalence of non-drinkers was reported amongst those practising ophthalmology and pathology respectively. The prevalence of drinking multiple times per week was significantly higher amongst consultants, males, those who were married/ 
Table 2 Cross tabulation of demographic characteristics with smoking habits

\begin{tabular}{|c|c|c|c|c|}
\hline Characteristic & Non-smoker \% (N) & Occasional smoker \% (N) & Daily smoker \% (N) & $x^{2}$ \\
\hline \multicolumn{5}{|l|}{ Age } \\
\hline$\leq 30$ & $86.8(302)$ & $10.9(38)$ & $2.3(8)$ & \multirow[t]{4}{*}{$14.97^{*}$} \\
\hline $31-40$ & $90.9(479)$ & $7(37)$ & $2.1(11)$ & \\
\hline $41-50$ & $93.1(432)$ & $4.5(21)$ & $2.4(11)$ & \\
\hline$>50$ & 90.7 (353) & $5.9(23)$ & $3.3(13)$ & \\
\hline \multicolumn{5}{|l|}{ Sex } \\
\hline Male & $88(778)$ & $8.6(75)$ & $2.6(23)$ & \multirow[t]{2}{*}{$8.83^{* *}$} \\
\hline Female & $92.6(796)$ & $5(43)$ & $2.4(21)$ & \\
\hline \multicolumn{5}{|l|}{ Work Grade } \\
\hline Consultant & $92.7(873)$ & $4.8(45)$ & $2.5(24)$ & \multirow[t]{2}{*}{$13.77^{* * *}$} \\
\hline Trainee & $88.2(703)$ & $9.3(74)$ & $2.5(20)$ & \\
\hline \multicolumn{5}{|l|}{ Sex and Work Grade } \\
\hline Male (C) & $91.5(520)$ & $6.2(35)$ & $2.3(13)$ & \multirow[t]{2}{*}{$12.93^{* *}$} \\
\hline Male (T) & $83.8(258)$ & $13(40)$ & $3.2(10)$ & \\
\hline Female (C) & $94.4(352)$ & $2.7(10)$ & $2.9(11)$ & \multirow[t]{2}{*}{$8.01^{*}$} \\
\hline Female (T) & $91.2(444)$ & $6.8(33)$ & $2.1(10)$ & \\
\hline \multicolumn{5}{|l|}{ Marital status } \\
\hline Married or cohabitating & $92.4(1125)$ & $5.1(62)$ & $2.5(31)$ & \multirow[t]{3}{*}{$21.57^{* * *}$} \\
\hline Single & $86.2(381)$ & $11.1(49)$ & $2.7(12)$ & \\
\hline Divorced or separated & $88.5(46)$ & $11.5(6)$ & $0(0)$ & \\
\hline \multicolumn{5}{|l|}{ Nationality } \\
\hline Irish & $90.9(1360)$ & $6.7(100)$ & $2.4(36)$ & \multirow[t]{2}{*}{1.14} \\
\hline Non-Irish & $88.9(216)$ & $7.8(19)$ & $3.3(8)$ & \\
\hline \multicolumn{5}{|l|}{ Specialty } \\
\hline Anaesthetics & $87.9(217)$ & $9.7(24)$ & $2.4(6)$ & \multirow[t]{9}{*}{$28.98^{*}$} \\
\hline Emergency & $81.2(69)$ & $12.9(11)$ & $5.9(5)$ & \\
\hline Medicine & $92.9(407)$ & $5.3(23)$ & $1.8(8)$ & \\
\hline Obstetrics \& Gynaecology & $86.9(93)$ & $8.4(9)$ & $4.7(5)$ & \\
\hline Ophthalmology & $91.4(32)$ & $5.7(2)$ & $2.9(1)$ & \\
\hline Paediatrics & $93.9(155)$ & $6.1(10)$ & $0(0)$ & \\
\hline Pathology & $92(127)$ & $4.3(6)$ & $3.6(5)$ & \\
\hline Psychiatry & $92.8(259)$ & $4.3(12)$ & $2.9(8)$ & \\
\hline Surgery & $88.4(214)$ & $9.1(22)$ & $2.5(6)$ & \\
\hline \multicolumn{5}{|l|}{ Mean Hours Worked/Week } \\
\hline$<40$ & $88.5(108)$ & $6.6(8)$ & $4.9(6)$ & \multirow[t]{4}{*}{6.31} \\
\hline $40-80$ & $91(1287)$ & $6.7(95$ & $2.2(31)$ & \\
\hline$>80$ & 86.9 (113) & $8.5(11)$ & $4.6(6)$ & \\
\hline Total & $90.6(1576)$ & $6.8(119)$ & $2.5(44)$ & \\
\hline
\end{tabular}

${ }^{*} P$ value $<.05{ }^{* *} P$ value $<.01{ }^{* * *} P$ value $\leq .001$

cohabitating, Irish nationals, those who worked under $40 \mathrm{~h}$ per week and doctors aged over 50, compared to their respective counterparts. The highest prevalence of drinking multiple times per week by specialty was reported by pathologists and the lowest was seen in surgeons (Table 3).
A significantly higher proportion of males engaged in binge drinking on a typical drinking occasion compared to their female counterparts $(p=.000) .20 .9 \%$ of trainees engaged in binge drinking on a typical occasion, compared with $6.6 \%$ of consultants $(\mathrm{p}=.000)$. Furthermore, $37.8 \%$ of male trainees engage in binge drinking on a 


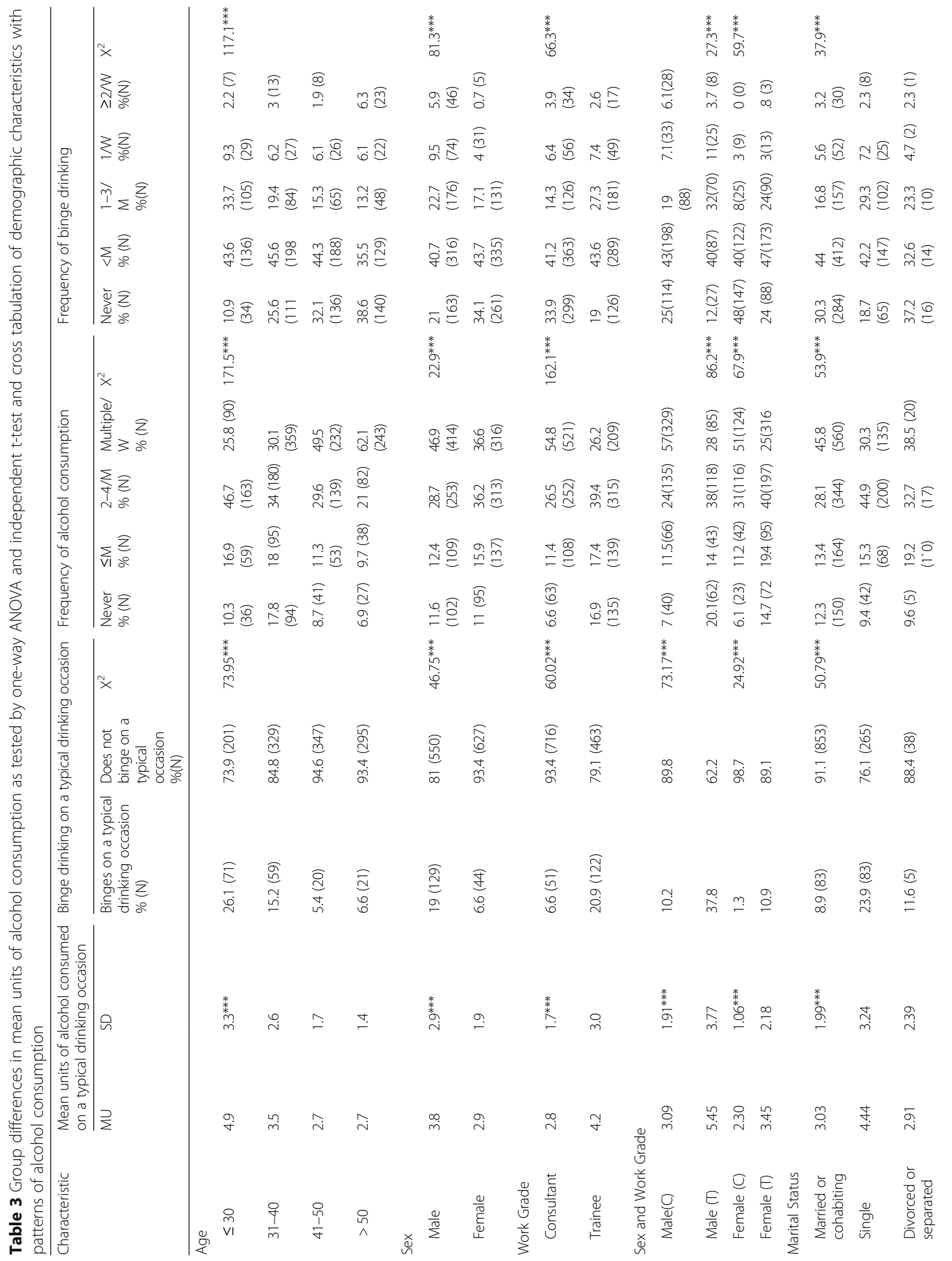


O' Keeffe et al. BMC Public Health $\quad$ (2019) 19:179

Page 7 of 15

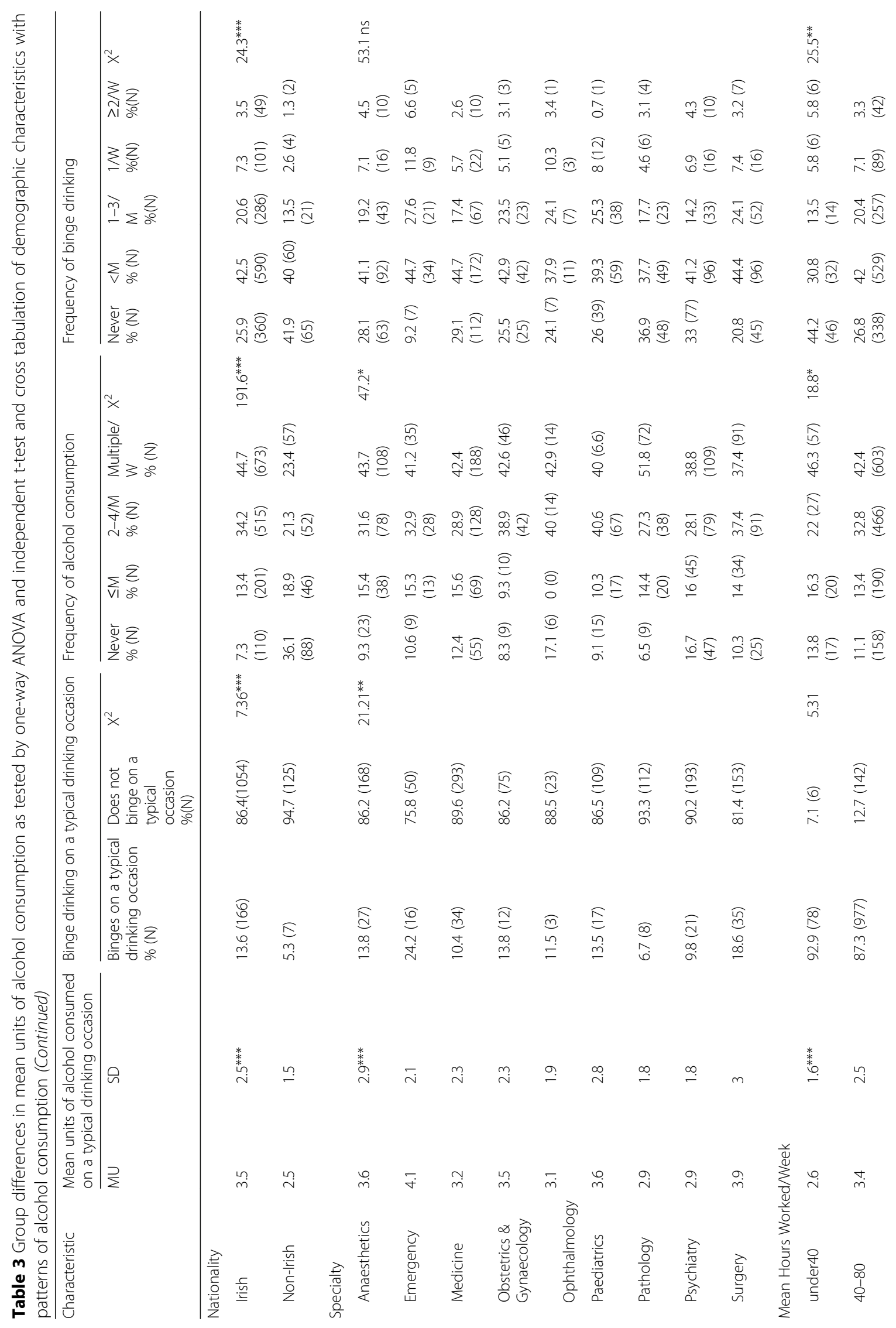




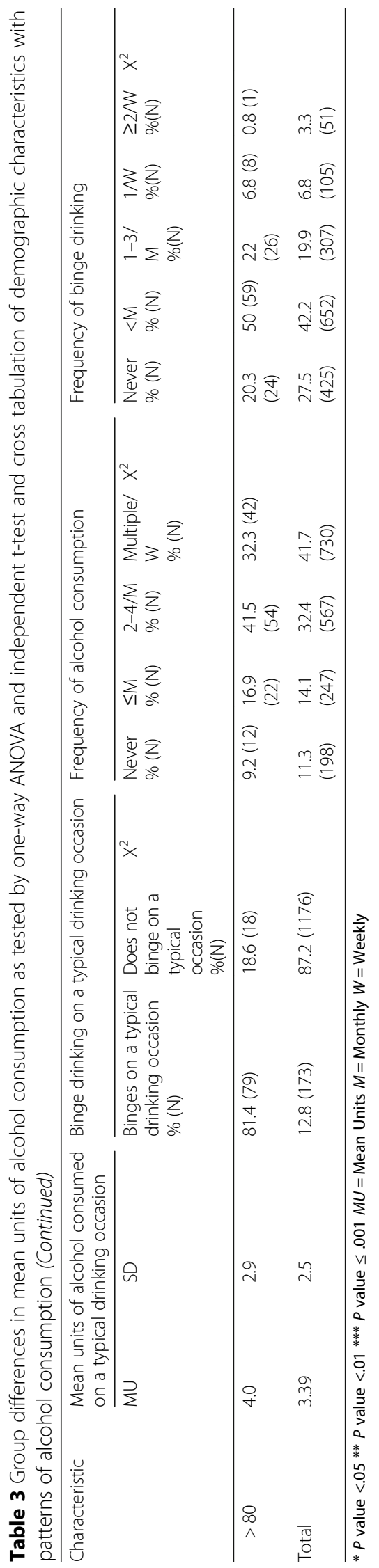


typical drinking occasion, compared with $10.9 \%$ of female trainees $(p=.0001)$. Only $1.3 \%$ of female consultants reported engaging in binge drinking on a typical occasion, significantly less than the $10.2 \%$ of male consultants ( $p$ $=.0001$ ). Single doctors were significantly more likely to binge drink on a typical drinking occasion compared to their married/cohabitating colleagues $(\mathrm{p}=.000)$. Binging on a typical occasion was significantly more prevalent amongst those holding Irish nationality. The highest and lowest prevalence of binging on a typical occasion were observed in doctors practising in emergency medicine and pathology respectively (Table 3 ).

\section{Physical activity}

Almost one fifth (19.1\%) of all doctors surveyed reported engaging in Health Enhancing Physical Activity (HEPA), while a quarter $(24.5 \%)$ were inactive. Compared to females, males had a higher prevalence of HEPA and a lower prevalence of inactivity. Trainees had a higher prevalence of inactivity and a lower prevalence of HEPA than consultants. In particular, male consultants demonstrated a significantly lower prevalence of inactivity and a significantly higher prevalence of HEPA when compared to male trainees, female trainees and female consultants. When comparing based on specialty, the highest prevalence of HEPA was observed in anaesthetists, while ophthalmologists had the highest rates of physical inactivity. Doctors working more than $80 \mathrm{~h}$ per week engaged in HEPA at higher rates than their colleagues who worked less than $40 \mathrm{~h}$ per week. Rates of inactivity were almost equal in both groups (Table 4).

\section{Logistic regression analysis Smoking}

The adjusted binary logistic regression model identified sex and marital status as significantly associated with smoking when controlling for specialty, age, work grade, mean hours worked per week and nationality (Table 5). Males were significantly more likely to smoke than females (OR 1.8; 95\% CI -1.26-2.62). Doctors who were single were significantly more likely to smoke compared to their colleagues who were married/cohabitating (OR 1.76; 95\% CI - 1.13-2.72) (Table 5).

\section{Binge drinking on a typical drinking occasion}

Sex, nationality, age group and marital status were significantly associated with binge drinking on a typical occasion in the binary logistic regression model when specialty, work grade and mean working hours per week were controlled for (Table 5). Males were nearly 8 times more likely to binge drink on a typical occasion compared with female colleagues (OR 7.61; 95\% CI 4.8212.03). Non-Irish nationals were four times less likely to binge drink compared to their Irish counterparts (OR
0.25; 95\% CI 0.11-0.58). Doctors under 30 years of age were almost 5 times as likely to binge on a typical occasion compared to those over 50 (OR 4.85; 95\% CI 2.3415.89). Single doctors were more than twice as likely to binge drink on a typical drinking occasion when compared to their married/cohabitating colleagues (OR 2.3; 95\% CI 1.44-3.67). Medical physicians were half as likely to engage in binge drinking on a typical drinking occasion compared to the reference group of surgeons (OR 0.49; 95\% CI 0.26-0.93).

\section{Physical inactivity}

Sex, work grade, age group and mean hours worked were all significantly associated with physical inactivity in the adjusted binary logistic regression model when controlling for nationality, specialty and marital status (Table 5). Compared to females, males were significantly less likely to be inactive (OR 0.75 ; 95\% CI $0.58-0.97$ ). Consultants were significantly less likely to be inactive compared with trainees (OR 0.54; 95\% CI 1.12-2.75). Doctors aged 40-50 were significantly more likely to be inactive compared to the reference group of doctors aged over 51 (OR 1.49; 95\% CI 1.02-2.16). Doctors working $40-80 \mathrm{~h} /$ week were significantly less likely to be inactive compared to those working more than $80 \mathrm{~h}$ per week (OR 0.56; 95\% CI 0.36-0.87). Anaesthetists were half as likely to be inactive as their surgical colleagues (OR 0.57; 95\% CI 0.34-0.93); however, no other specialty was found to be significantly more or less likely to be inactive compared with the reference group of surgeons (Table 5).

\section{Comparison of lifestyle behaviours of doctors with general working age population and cohort matched for age, social class and education}

The prevalence of daily smoking was significantly less in the doctor cohort compared to both the general working age population and the matched cohort (Table 6).

There were significantly more non-drinkers in the general population compared to the doctor cohort. The prevalence of drinking multiple times per week was significantly higher amongst doctors compared with the general working age population, but not compared to the matched cohort. Compared to doctors, the prevalence of binge drinking on a typical occasion was significantly higher amongst both the general working age population and the matched cohort. On average, doctors consumed significantly less alcohol on a typical drinking occasion than either the general working age population or the matched cohort.

Doctors engaged in HEPA at a significantly lower rate than both the general working age population and the matched cohort. However, their prevalence of physical 
Table 4 Cross tabulation of demographic characteristics with levels of physical activity

\begin{tabular}{|c|c|c|c|c|}
\hline Characteristic & Inactive & Minimally Active & HEPA & $x^{2}$ \\
\hline \multicolumn{5}{|l|}{ Age } \\
\hline$\leq 30$ & $22.1(75)$ & $56(190)$ & $21.8(74)$ & \multirow[t]{4}{*}{$34.13^{* * *}$} \\
\hline $31-40$ & $30.1(153)$ & $55.5(282)$ & $14.4(73)$ & \\
\hline $41-50$ & $25.6(112)$ & $58.1(254)$ & $16.2(71)$ & \\
\hline$>50$ & $17.4(64)$ & $56.4(207)$ & $26.2(96)$ & \\
\hline \multicolumn{5}{|l|}{ Sex } \\
\hline Male & $21.2(178)$ & $57.9(486)$ & $20.9(175)$ & \multirow[t]{2}{*}{$11.22^{* *}$} \\
\hline Female & $27.9(229)$ & $54.9(450)$ & $17.2(141)$ & \\
\hline \multicolumn{5}{|l|}{ Work Grade } \\
\hline Consultant & $21.4(190)$ & $58.7(521)$ & $19.9(177)$ & \multirow[t]{2}{*}{$9.87^{* *}$} \\
\hline Trainee & $28(217)$ & $53.9(417)$ & $18.1(140)$ & \\
\hline \multicolumn{5}{|l|}{ Sex and Work Grade } \\
\hline Male (C) & $17.2(93)$ & $60.1(325)$ & $22.7(123)$ & \multirow[t]{2}{*}{$15.42^{* * *}$} \\
\hline Male $(T)$ & $28.5(85)$ & $54(161)$ & $17.4(52)$ & \\
\hline Female $(C)$ & $28(97)$ & $56.4(195)$ & $15.6(54)$ & \multirow[t]{2}{*}{1.12} \\
\hline Female $(T)$ & $27.8(132)$ & $53.8(255)$ & $18.4(87)$ & \\
\hline \multicolumn{5}{|l|}{ Marital status } \\
\hline Married or cohabitating & 25.7 (298) & $56.6(656)$ & $17.6(204)$ & \multirow[t]{3}{*}{6.55} \\
\hline Single & $22.4(96)$ & $55.4(237)$ & $22.2(95)$ & \\
\hline Divorced or separated & $18.0(9)$ & $58(29)$ & $24(12)$ & \\
\hline \multicolumn{5}{|l|}{ Nationality } \\
\hline Irish & $23.5(335)$ & $57(813)$ & $19.6(279)$ & \multirow[t]{2}{*}{5.95} \\
\hline Non-Irish & $30.6(72)$ & $53.2(125)$ & $16.2(38)$ & \\
\hline \multicolumn{5}{|l|}{ Specialty } \\
\hline Anaesthetics & $15(35)$ & $58.1(136)$ & $26.9(63)$ & \multirow[t]{9}{*}{$37.40^{* *}$} \\
\hline Emergency & $27.5(22)$ & $55(44)$ & $17.5(14)$ & \\
\hline Medicine & $23.7(101)$ & $54.9(234)$ & $21.4(91)$ & \\
\hline Obstetrics \& Gynaecology & $29.4(30)$ & $49(50)$ & $21.6(22)$ & \\
\hline Ophthalmology & $32.3(10)$ & $48.4(15)$ & $19.4(6)$ & \\
\hline Paediatrics & $22.2(35)$ & $57.6(91)$ & $20.3(32)$ & \\
\hline Pathology & $25.2(33)$ & $62.6(82)$ & $12.2(16)$ & \\
\hline Psychiatry & $30.9(82)$ & $56.2(149)$ & $12.8(34)$ & \\
\hline Surgery & $25(58)$ & $58.6(136)$ & $16.4(38)$ & \\
\hline \multicolumn{5}{|l|}{ Mean Hours Worked/Week } \\
\hline$<40$ & $30.6(34)$ & $56.8(63)$ & $12.6(14)$ & \multirow[t]{4}{*}{$9.701^{*}$} \\
\hline $40-80$ & $23.1(313)$ & $57.3(777)$ & $19.7(267)$ & \\
\hline$>80$ & $31.2(39)$ & $48(60)$ & $20.8(26)$ & \\
\hline Total & $24.5(407)$ & $56.4(938)$ & 19.1 (317) & \\
\hline
\end{tabular}

${ }^{*} P$ value $<.05{ }^{* *} P$ value $<.01{ }^{* * *} P$ value $\leq .001$

inactivity was also significantly lower than in the general working age population.

\section{Discussion}

This study aimed to assess the lifestyle behaviours of hospital doctors working in Ireland, and to compare the prevalence of these behaviours amongst doctors to that of the general working population in Ireland. The lifestyle behaviours of doctors have attracted significant attention in recent years. However, little is known about the Irish context and few studies have compared doctor's lifestyle behaviours to those of the 
Table 5 Adjusted odds ratio $(95 \%$ Cl) of variables associated with lifestyle risk factors

\begin{tabular}{|c|c|c|c|c|c|c|}
\hline \multirow[t]{2}{*}{ Characteristic } & \multicolumn{2}{|l|}{ Smoking } & \multicolumn{2}{|l|}{ Binge Drinking } & \multicolumn{2}{|l|}{ Physical Inactivity } \\
\hline & $\overline{\mathrm{OR}(\mathrm{Cl})}$ & $p$ & $\overline{\mathrm{OR}(\mathrm{Cl})}$ & $p$ & $\overline{\mathrm{OR}(\mathrm{Cl})}$ & $p$ \\
\hline \multicolumn{7}{|l|}{ Age } \\
\hline$\leq 30$ & $.87(.34-2.21)$ & .765 & $4.85(1.8-13.04)$ & .002 & $.76(.41-1.41)$ & .378 \\
\hline $31-40$ & $.60(.26-1.35)$ & .214 & $2.06(.88-4.79)$ & .095 & $1.20(.72-2.01)$ & .48 \\
\hline $41-50$ & $.77(.45-1.32)$ & .336 & $.93(.47-1.84)$ & .839 & $1.49(1.02-2.16)$ & .036 \\
\hline$>50$ & 1 & & 1 & & 1 & \\
\hline \multicolumn{7}{|l|}{ Sex } \\
\hline Male & $1.8(1.26-2.62)$ & .002 & $7.61(4.82-12.03)$ & .000 & $.75(.58-.97)$ & .026 \\
\hline Female & 1 & & 1 & & 1 & \\
\hline \multicolumn{7}{|l|}{ Work Grade } \\
\hline Consultant & $.55(.26-1.17)$ & .119 & $.57(.26-1.23)$ & .151 & $.54(.35-.86)$ & .008 \\
\hline Trainee & 1 & & 1 & & 1 & \\
\hline \multicolumn{7}{|l|}{ Nationality } \\
\hline Irish & 1 & .928 & 1 & .001 & 1 & .116 \\
\hline Non-Irish & $1.02(.62-1.68)$ & & $.25(.11-.58)$ & & $1.31(.94-1.83)$ & \\
\hline \multicolumn{7}{|l|}{ Specialty } \\
\hline Anaesthetics & 1.07 (.59-1.96) & .822 & $.80(.42-1.56)$ & .514 & $.57(.34-.93)$ & .026 \\
\hline Emergency & $1.94(.94-4.01)$ & .075 & $1.24(.55-2.78)$ & .604 & $1.22(.66-2.26)$ & .522 \\
\hline Obstetrics and Gynaecology & $1.45(.70-3.02)$ & .317 & $1.03(.45-2.35)$ & .946 & $1.21(.68-2.14)$ & .516 \\
\hline Ophthalmology & $.98(.27-3.57)$ & .979 & $1.17(.30-4.57)$ & .826 & $1.36(.56-3.29)$ & .492 \\
\hline Paediatrics & $.60(.27-1.33)$ & .208 & $.87(.40-1.86)$ & .709 & $.87(.52-1.46)$ & .592 \\
\hline Pathology & $.95(.43-2.06)$ & .888 & $.68(.28-1.66)$ & .398 & $1.08(.63-1.86)$ & .772 \\
\hline Physicians & $.69(.38-1.30)$ & .214 & $.49(.26-.93)$ & .03 & $1.04(.68-1.57)$ & .868 \\
\hline Psychiatry & $.68(.34-1.37)$ & .284 & $.80(.39-1.65)$ & .54 & $1.22(.77-1.93)$ & .401 \\
\hline Surgery & 1 & & 1 & & 1 & \\
\hline \multicolumn{7}{|l|}{ Mean Hours Worked } \\
\hline$<40$ & $1.58(.67-3.71)$ & .295 & $1.28(.40-4.17)$ & .677 & $.70(.38-1.30)$ & .259 \\
\hline $40-80$ & $.86(.46-1.59)$ & .63 & $1.35(.66-2.76)$ & .41 & $.56(.36-87)$ & .010 \\
\hline$>80$ & 1 & & 1 & & 1 & \\
\hline \multicolumn{7}{|l|}{ Marital Status } \\
\hline Married or cohabitating & 1 & & 1 & & 1 & \\
\hline Single & $1.76(1.13-2.72)$ & .012 & $2.30(1.44-3.67)$ & .000 & $.75(.55-1.03)$ & .079 \\
\hline Divorced or separated & $1.74(.70-4.31)$ & .23 & $2.49(.85-7.29)$ & .095 & $.52(.28-1.21)$ & .128 \\
\hline
\end{tabular}

general population $[10,16]$. The prevalence of smoking was less than $10 \%$, which was in the mid-range for a developed nation - previous evidence shows that rates of smoking amongst hospital physicians range from 3\% in Australia [12] to $15 \%$ in Denmark [26]. Consistent with much of the published data in this area, our results showed a significantly higher prevalence of smoking amongst males [12]. The findings from the adjusted model indicate that marital status is also significantly associated with smoking, with single doctors being significantly more likely to smoke compared with their married/cohabitating counterparts. This finding is consistent with previous studies of physicians [10] and also with studies of non-physician cohorts [27].

The majority of smokers smoked occasionally, and the prevalence of daily smoking was low at $2.5 \%$. While daily smoking is associated with greater health risks, occasional smoking is associated with a significant increased risk of health problems when compared with non-smokers [28].

In line with previous studies showing lower smoking rates amongst health care professionals compared to other professionals [11], doctors were significantly less likely to smoke than either the general population or the matched cohort. 
Table 6 Comparison of prevalence of lifestyle behaviours between hospital doctors working in Ireland and general working age population and cohort matched for age, social class and education

\begin{tabular}{|c|c|c|c|}
\hline Characteristic & Doctors \% & General working age population $\%\left(X^{2}\right)$ & Matched Cohort \% $\left(X^{2}\right)$ \\
\hline \multicolumn{4}{|l|}{ Smoking } \\
\hline Non-Smoker & $90.6 \%$ & $73.9 \%(211.01)^{* * *}$ & $85.5 \%(12.56)^{* * *}$ \\
\hline Occasional & $6.8 \%$ & $4.7 \%(12.06)^{* * *}$ & $5.9 \%(.67)$ \\
\hline Daily & $2.5 \%$ & $21.4 \%(332.13)^{* * *}$ & $8.6 \%(43.27)^{* * *}$ \\
\hline \multicolumn{4}{|l|}{ Alcohol } \\
\hline \multicolumn{4}{|l|}{ Frequency of alcohol consumption } \\
\hline Never & $11.4 \%$ & $18.3 \%(44.86)^{* * *}$ & $9.6 \%(1.46)$ \\
\hline Monthly or less & $14.2 \%$ & $25.1 \%(89.20)^{* * *}$ & $19.2 \%(9.09)^{* *}$ \\
\hline 2-4 times/month & $32.5 \%$ & $30 \%(3.91)^{*}$ & $31.4 \%(0.27)$ \\
\hline Multiple times/week & $41.9 \%$ & $26.6 \%(143.56)^{* * *}$ & $39.8 \%(0.76)$ \\
\hline Binges on a typical drinking occasion & $12.8 \%$ & $39.5 \%(326.97)^{* * *}$ & $29.5 \%(78.33)^{* * *}$ \\
\hline Mean units consumed on a typical drinking occasion & 3.4 & 5.6 (SD: 4.16) ${ }^{* * *}$ & 4.7 (SD: 3.47) ${ }^{* * *}$ \\
\hline \multicolumn{4}{|l|}{ Physical activity } \\
\hline Inactive & $24.5 \%$ & $29.5 \%(15.62)^{* * *}$ & $26.3 \%(.847)$ \\
\hline Minimally active & $56.4 \%$ & $37.5 \%(184.78)^{* * *}$ & $39.9 \%(51.95)^{* * *}$ \\
\hline Health enhancing physical activity & $19.1 \%$ & $33 \%(15.62)^{* * *}$ & $33.8 \%(56.62){ }^{* * *}$ \\
\hline
\end{tabular}

Between group differences: ${ }^{*} P$ value $<.05{ }^{* *} P$ value $<.01{ }^{* * *} P$ value $\leq .001$ (Reference groups compared to doctors)

The rate of abstinence from alcohol was significantly higher amongst trainees compared with consultants, similar to trends observed in other European countries [29]. Consultants drank alcohol multiple times per week at a significantly higher rate than trainees but drank significantly lower volumes on a typical drinking occasion.

Irish nationals, males, doctors under 30 and doctors who were single were significantly more likely to binge on a typical occasion when compared to their respective counterparts. Our finding that male doctors tend to engage in harmful drinking at a significantly greater rate than females concurs with the majority of research in this area [10, 17], save for one recent study [30]. International evidence suggests that younger doctors tend to be more moderate in their drinking habits compared to their older colleagues [29], contrary to our findings. This discrepancy may reflect cultural differences amongst the general populations from which doctors are drawn as a similar pattern was observed in the Healthy Ireland study [25], which demonstrated that the prevalence of binge drinking in Ireland tends to decrease with age. Studies examining the relationship between the marital status of doctors and their patterns of alcohol use have demonstrated mixed results, with some finding that single doctors are more likely to engage in hazardous drinking when compared with their married colleagues $[10,15]$ and others finding the opposite relationship [30]. Surgeons were found to be twice as likely to engage in binge drinking as their medical colleagues. This concurs with previous research indicating higher rates of hazardous alcohol consumption amongst surgeons [17], however, this finding has not been consistently demonstrated [31].

When compared to the general working age population, there was a significantly lower prevalence of abstinence from alcohol amongst hospital doctors and they also reported higher prevalence of drinking multiple times per week. However, doctors reported drinking significantly less on a typical drinking occasion and were significantly less likely to binge on a typical drinking occasion compared to either group. Our findings suggest that while doctors in Ireland are more likely to be drinkers, they are less likely to engage in hazardous drinking behaviours. International data comparing doctors' drinking habits to that of the general population has demonstrated mixed results, with results in Germany showing healthier habits amongst doctors [17], while results in Switzerland indicate more hazardous drinking amongst doctors [10].

The majority of doctors (75.5\%) met the minimum weekly exercise recommendation of at least $150 \mathrm{~min}$ of moderate intensity exercise per week. Physical inactivity was significantly associated with sex, work grade, mean hours worked per week and one specialty. Males and consultants were significantly less likely to be inactive compared to their respective colleagues. Previous studies have also demonstrated a higher prevalence of inactivity amongst females [32] and trainees [33]. Those working more than $80 \mathrm{~h}$ per week were significantly more likely to be inactive compared to those working $40-80 \mathrm{~h}$ per 
week. Anaesthetists were significantly less likely to be inactive compared with their surgical colleagues, however, there were no significant difference in levels of inactivity between the remaining specialties and the reference category of surgeons. The prevalence of inactivity was lower in our cohort compared to previous international studies. For example, only $49.3 \%$ of Catalan doctors [34] and $53 \%$ of Brazilian doctors [35] were shown to meet the minimum weekly exercise target of $150 \mathrm{~min} /$ week.

Engaging in health enhancing physical activity was the main health behaviour identified in the study where the general population outperformed doctors. Compared with the general working age population and the matched cohort, doctors had a lower prevalence of physical inactivity; however, both comparison groups engaged in health enhancing physical activity at a significantly higher rate than doctors in Ireland. Studies comparing physicians' exercise habits to those of their patients have demonstrated mixed results. Doctors in Bahrain and Catalonia are less physically active than their respective general populations [16, 34], whereas doctors in the U.S. engage in physical activity at higher rates than other professions in that country [36]. Previous studies have demonstrated an association between physical inactivity and long working hours [37]; however, this finding was not fully supported by our study. While doctors working over $80 \mathrm{~h} /$ week were more likely to be inactive compared to their colleagues working 40$80 \mathrm{~h} /$ week, they engaged in HEPA at higher rates than those working less than $40 \mathrm{~h}$ /week. Consequently, we cannot surmise with confidence that longer working hours explain the observed differences in rates of engaging in health enhancing physical activity between doctors working in hospitals in Ireland and the general population.

Some interventions aimed at improving the health behaviours of medical students and residents have shown positive results. "Self-awareness" and "self-care" interventions consisting of a lecture and written information about self-care habits, and a group discussion of self-care issues led to an improvement in the sleeping habits and activity levels of first year medical students compared to a control group who did not participate in the intervention programme. No change was observed in patterns of alcohol consumption [38]. An elective, team-based, 12-week, incentivized exercise programme designed for medical residents and fellows resulted in an increase in the percentage of people that met the recommendations for activity, a better quality of life and lower burnout scores compared to a control group that did not participate in the programme [39]. To our knowledge, no specific interventions targeted at medical students or residents have led to a reduction in the prevalence of binge drinking $[23,40$, 41]; however, it has been suggested that using former impaired healthcare professionals to teach in medical schools and in hospitals may be an effective strategy [41]. Future research should investigate which strategies are most effective for decreasing alcohol misuse among physicians in training.

\section{Strengths and limitations}

This study reports on findings from the first national survey of hospital doctors working within the same health system in Ireland and it is also the first study seeking to compare the lifestyle behaviours of doctors to those of the general population in Ireland. The response rate of $55 \%$ is reasonably high, given that studies involving doctors tend to have poor response rates [42]. The study included a wide cohort of hospital doctors representing almost all specialities found within the Irish health system and the sample size was deemed robust enough for the analysis performed; consequently, we are satisfied that our results are broadly representative of the target population; however, we do note that there was a higher representation of respondents holding Irish nationality when compared to the actual number of Irish graduates working within Irish hospitals [19], which may indicate some response bias.

The use of the same validated instruments for both our study and the Healthy Ireland study allow for ready comparison of many of the results.

However, due to methodological differences in how data relating to mean hours worked per week were recorded in the Healthy Ireland study and due to the poor response rate to this question in that study $(<10 \%)$, we could not accurately compare the mean working hours between our sample and the two reference groups.

Similarly, there was a slight methodological difference between the method used to assess alcohol consumption in this study and the one used in the Healthy Ireland survey. It has been demonstrated that people are more likely to underreport socially undesirable behaviours in the presence of an interviewer [43]. The sensitivity of the topic could have led to an underestimation of the prevalence of the relevant health risk behaviours in both our study sample and the general population data, as studies have demonstrated that sensitive questions provoke an increase in non-response and underreporting of socially undesirable behaviours [43]. To the best of our knowledge, no studies have addressed whether doctors are more or less likely to report socially undesirable behaviours than the general population. Similarly, we have not encountered any research into whether response rates to sensitive survey questions differs by medical specialty.

Aside from a longitudinal design, future studies should consider including other health behaviours, such as body mass index, dietary and sleeping habits and the use of illicit substances as well as their association with the likelihood of providing advice to patients on lifestyle behaviours. As this study was performed as part of a larger 
study exploring general and workplace wellbeing of doctors in Ireland [19], we were limited by the number of items used to assess health behaviours in order to avoid an excessively long questionnaire which might have impacted upon response rate.

\section{Conclusions}

This study identified populations of hospital doctors in Ireland who were at increased risk of engaging in health risk behaviours. Male doctors were significantly more likely to smoke and engage in binge drinking compared to females. In particular, male trainees smoked and engaged in hazardous drinking behaviours at far greater rates than their colleagues. Trainees and female doctors were significantly more likely to be physically inactive when compared with their respective colleagues. Educational interventions addressing these issues targeted at these subgroups should be considered.

Overall, hospital doctors working in Ireland exhibit healthier lifestyle behaviours than both the general working age population and a cohort matched for age, socioeconomic status and level of education. This was demonstrated in lower rates of smoking, lower rates of hazardous alcohol consumption and lower levels of physical inactivity. However, their engagement in health enhancing physical activity was lower than the general population. This is an area in which doctors in Ireland could improve, as the increased health benefits associated with higher levels of physical activity are well established $[44,45]$.

The health and wellbeing of doctors is essential to the optimal functioning of a healthcare system [5]. Strong consideration should be given to implementing intervention programmes addressing the lifestyle behaviours of doctors, ideally during the pre-clinical years of undergraduate training.

\section{Additional files}

Additional file 1: Study questionnaire; copy of the relevant sections of the questionnaire used in the study. (DOCX $133 \mathrm{~kb}$ )

Additional file 2: Information leaflet included with the questionnaire; this detailed the purpose and scope of the study. (DOCX $54 \mathrm{~kb}$ )

\section{Abbreviations}

ANOVA: Analysis of Variance; C: Consultant; Cl: Confidence Interval; HEPA: Health Enhancing Physical Activity; IPAQ-SF: The International Physical Activity Questionnaire Short Form; M: Monthly; MU: Mean Units; N: Number; OR: Odds Ratio; SD: Standard Deviation; T: Trainee; W: Weekly

\section{Acknowledgements}

The authors express gratitude to all the doctors who took time to complete the survey and share with us their insight and experience. We are grateful to all the postgraduate training bodies who participated in the study and facilitated the data collection. We thank the members of the Steering Group for their guidance and several members of the research, education and communications departments of the Royal College of Physicians of Ireland for their expertise and support, in particular Gillian Walsh who was key to the original conception and design of the overall project. We thank Finbarr
Leacy of the Royal College of Surgeons in Ireland for providing statistical guidance. We thank "Healthy Ireland" the Irish Social Science Data Archive (ISSDA) for making the Healthy Ireland 2015 data set available to us. We acknowledge the assistance of Dr. Fenton Howell and Dr. Miriam Owen (Department of Health) for their help in the choice of questions on tobacco consumption. We also acknowledge the Human Resources National Directorate of the Health Service Executive as well as the Royal College of Physicians of Ireland, the Royal College of Surgeons in Ireland and the College of Anaesthetists for providing generous financial support.

\section{Funding}

Financial support was provided by the Human Resources National Directorate of the Health Service Executive as well as by the Royal College of Physicians of Ireland, the Royal College of Surgeons in Ireland and the College of Anaesthetists. This covered the cost of consumables and data entry to SPSS.

\section{Availability of data and materials}

As per the ethics approval, the data will not be shared outside of the participating research institutions. Any sharing of the data beyond the group will be subject to review by the host institution (Royal College of Physicians of Ireland) and to independent research ethics application. Any queries on how to access the dataset should be directed to research@rcpi.ie.

\section{Authors' contributions}

$\mathrm{BH}$ conceived and designed the original study protocol. AOK conceived the research question for this paper, conducted a relevant literature review, obtained the data set from the healthy Ireland study, performed the statistical analysis and wrote the first draft of the manuscript. $\mathrm{BH}$ and LP contributed to subsequent drafts, and LP provided statistical advice. All authors have read and approved this manuscript.

\section{Ethics approval and consent to participate}

The study was approved by the Research Ethics Committee of Royal College of Physicians of Ireland December 2013 (RCPI RECSAF 20).

An extensive participant information leaflet was included with the questionnaire outlining the purpose and scope of the study (Additional file 2). The leaflet also explained that the information was being gathered anonymously to ensure confidentiality and that the response to the questionnaire was indicative of consent. Specifically, potential participants were informed that "by responding to the questionnaire either electronically or by post, you are consenting to participate." This method of consent was approved by the Research Ethics Committee of Royal College of Physicians of Ireland December 2013 (RCPI RECSAF 20).

\section{Consent for publication}

Not applicable.

The Healthy Ireland 2015 data set can be accessed via the Irish Social Science Data Archive - www.ucd.ie/issda.

\section{Competing interests}

The authors declare that they have no competing interests.

\section{Publisher's Note}

Springer Nature remains neutral with regard to jurisdictional claims in published maps and institutional affiliations.

Received: 4 October 2018 Accepted: 17 January 2019

Published online: 11 February 2019

\section{References}

1. Doll R, Peto R, Boreham J, Sutherland I. Mortality from cancer in relation to smoking: 50 years observations on British doctors. Br J Cancer. 2005;92:426-9.

2. Boyle P. Cancer, cigarette smoking and premature death in Europe: a review including the recommendations of European Cancer experts consensus meeting, Helsinki, October 1996. Lung Cancer. 1997;17:1-60.

3. World Health Organisation. Global status report on alcohol and health; 2014. p. 1-392.

4. Booth FW, Chakravarthy MV, Gordon SE, Spangenburg EE. Waging war on physical inactivity: using modern molecular ammunition against an ancient 
enemy. J Appl Physiol. 2002;93:3-30 Available from: http://jap.physiology. org/lookup/doi/10.1152/japplphysiol.00073.2002.

5. Taub S, Morin K, Goldrich MS, Ray P, Benjamin RM, Higginson D, et al. Physician health and wellness. Occup Med (Chic III). 2006;56:77-82.

6. Frank E, Segura C, Shen H, Oberg E. Predictors of Canadian physicians' prevention counseling practices. Can J Public Heal. 2010;101:390-5.

7. Lobelo F, de Quevedo IG. The evidence in support of physicians and health care providers as physical activity role models. Am J Lifestyle Med. 2016;10:36-52.

8. Elley CR. Effectiveness of counselling patients on physical activity in general practice: cluster randomised controlled trial. Bmj. 2003;326:793 Available from: http://www.bmj.com/cgi/doi/10.1136/bmj.326.7393.793.

9. Frank E, Dresner Y, Shani M, Vinker S. The association between physicians' and patients' preventive health practices. Can Med Assoc J. 2013;185:649-54.

10. Sebo P, Bouvier Gallacchi M, Goehring C, Künzi B, Bovier PA. Use of tobacco and alcohol by Swiss primary care physicians: a cross-sectional survey. BMC Public Health. 2007;7:5.

11. Dayoub E, Jena AB. Chronic Disease Prevalence and Healthy Lifestyle Behaviors among US Health Care Professionals. Mayo Clin Proc. 2015;90: 1659-62. Mayo Foundation for Medical Education and Research. https://doi. org/10.1016/j.mayocp.2015.08.002.

12. Smith $D R$, Leggat PA. An international review of tobacco smoking in the medical profession: 1974-2004. BMC Public Health 2007;7:115

13. Tan NC, Aw L, Khin LW, Thirumoorthy T, Lim SH, Tai BC, et al. How do primary care physicians in Singapore keep healthy? Singap Med J. 2014;55:155-9.

14. McGrady FP, McGlade KJ, Cupples ME, Tully MA, Hart N, Steele K. Questionnaire survey of physical activity in general practitioners (PHIT GP study). Ulster Med J. 2007;76:91-7.

15. Sørensen JK, Pedersen AF, Bruun NH, Christensen B, Vedsted P. Alcohol and drug use among Danish physicians. A nationwide cross-sectional study in 2014. Dan Med J. 2015;62:1-8.

16. Borgan SM, Jassim GA, Marhoon ZA, Ibrahim MH. The lifestyle habits and wellbeing of physicians in Bahrain: a cross-sectional study. BMC Public Health. 2015;15:1-7. https://doi.org/10.1186/s12889-015-1969-x.

17. Rosta J. Hazardous alcohol use among hospital doctors in Germany. Alcohol Alcohol. 2008;43:198-203.

18. O' Cathail M, O' Callaghan M. A profile of hospital consultants: the health practices of a cohort of medical professionals. Ir Med J. 2013;106:134-6.

19. Hayes B, Prihodova L, Walsh G, Doyle F, Doherty S. What's up doc? A national cross-sectional study of psychological wellbeing of hospital doctors in Ireland. BMJ Open. 2017;7:e018023

20. Raosoft. Raosoft sample size calculator. 2004. Available from: http://www. raosoft.com/samplesize.html

21. Harrington J, Perry I, Lutomski J, Morgan K, McGee H, Shelley E, Watson D, Barry M. SLAN 2007: Survey of Lifestyle, Attitudes and Nutrition in Ireland. Dietary Habits of the Irish Population. Dublin: Department of Health and Children; 2008. http://epubs.rcsi.ie/cgi/viewcontent.cgi?article=1002\&context=psycholrep.

22. Moskalewicz J, Sieroslawski J. Drinking population surveys guidance document for standardizing approach; 2010

23. Greene M, Johnson JA, Seale JP, Tindol A, Le KB, Clemow DD, et al. The prevalence of binge drinking among primary care residents. Subst Abus. 2017;38:292-6 Taylor \& Francis; Available from: https://doi.org/10.1080/ 08897077.2016 .1212778 .

24. Craig CLC, Marshall AL, Sjostrom M, Bauman AE, Booth ML, et al. International physical activity questionnaire: 12 country reliability and validity. Med Sci Sport Exerc. 2003;35:1-7.

25. Department of Health -Health and Well being programme. Healthy Ireland Survey, 2015 [dataset]. Version 1. Irish Social Science Data Archive. SN: 002100. 2015. http://www.ucd.ie/issda/data/healthyireland/.

26. Kannegaard PN, Kreiner S, Gregersen P, Goldstein H. Smoking habits and attitudes to smoking 2001 among hospital staff at a Danish hospital comparison with a similar study 1999. Prev Med (Baltim). 2005:41:321-7.

27. Broms U, Silventoinen K, Lahelma E, Koskenvuo M, Kaprio J. Smoking cessation by socioeconomic status and marital status: the contribution of smoking behavior and family background. Nicotine Tob Res. 2004;6:447-55.

28. The Royal College of Physicians of Ireland. Position statement: Occasional smoking and its associated health risks RCPI Policy Group on Tobacco June 2018. 2018. p. 1-9.

29. Rosta J, Aasland OG. Age differences in alcohol drinking patterns among Norwegian and German hospital doctors - a study based on national samples. Ger Med Sci GMS. 2010;8:Doc05.
30. Oreskovich MR, Shanafelt T, Dyrbye LN, Tan L, Sotile W, Satele D, et al. The prevalence of substance use disorders in American physicians. Am J Addict. 2015;24:30-8.

31. Hughes P, Storr C. Physician substance use by medical specialty. J Addcit Dis. 1999;18:23-37.

32. Frank E, Segura C. Health practices of Canadian physicians. Can Fam Physician. 2009;55:810-1.e1-7

33. Howe M, Leidel A, Krishnan SM, Weber A, Rubenfire M, Jackson EA. Patientrelated diet and exercise counseling: do providers' own lifestyle habits matter? Prev Cardiol. 2010;13:180-5.

34. Pardo A, McKenna J, Mitjans A, Camps B, Violán M. Physical activity level and lifestyle-related risk factors from Catalan physicians. Prev Med (Baltim). 2012:55:256-7.

35. Hidalgo KD, Mielke GI, Parra DC, Lobelo F, Simões EJ, Gomes GO, et al. Health promoting practices and personal lifestyle behaviors of Brazilian health professionals. BMC Public Health. 2016;16:1-10. https://doi.org/10. 1186/s12889-016-3778-2.

36. Bass K, McGeeney KUS. Physicians Set Good Health Example. Gallup. 2012; Available from: http://news.gallup.com/poll/157859/physicians-set-goodhealth-example.aspx?utm_source=alert\&utm_medium=email\&utm_ campaign=syndication\&utm_content=morelink\&utm_term=Health - USA Weight - Wellbeing - Well-Being Index.

37. Taris TW, Ybema JF, Beckers DGJ, Verheijden MW, Geurts SAE, Kompier MAJ. Investigating the associations among overtime work, health behaviors, and health: a longitudinal study among full-time employees. Int J Behav Med. 2011:18:352-60

38. Ball S, Bax A. Self-care in medical education: effectiveness of health-habits interventions for first-year medical students. Acad Med. 2002;77:911-7.

39. Weight CJ, Sellon JL, Lessard-Anderson CR, Shanafelt TD, Olsen KD, Laskowski ER. Physical activity, quality of life, and burnout among physician trainees: the effect of a team-based, incentivized exercise program. Mayo Clin Proc. 2013;88:1435-42. Elsevier Inc. https://doi.org/10.1016/..mayocp. 2013.09.010

40. Frank E, Elon L. A Quantitative assessment of a 4-year intervention that improved patient counseling through improving medical student health. MedGenMed. 2007;9(2):58.

41. Baldisseri MR. Impaired healthcare professional. Crit Care Med 2007;35(2 Suppl):S106-16.

42. Thorpe C, Ryan B, McLean SL, Burt A, Stewart M, Brown JB, et al. How to obtain excellent response rates when surveying physicians. Fam Pract. 2009; 26:65-8.

43. Tourangeau R, Yan T. Sensitive questions in surveys. Psychol Bull. 2007;133: 859-83.

44. Warburton DER, Nicol CW, Bredin SSD. R eview health benefits of physical activity : the evidence. Can Medial Assoc J. 2006;174:801-9.

45. Health Service Executive (HSE) and the Royal College of Physicians Ireland (RCPI). Policy Group on Physical Activity. In: "Physical Activity: Prescription for a Wonder Drug" - a policy statement by the Royal College of Physicians of Ireland's policy group on Physical Activity; 2016. https://www.rcpi.ie/wpcontent/uploads/2016/10/9637-001-Policy-Group-on-Physical-ActivityDIGITAL-v3.pdf.
Ready to submit your research? Choose BMC and benefit from:
- fast, convenient online submission
- thorough peer review by experienced researchers in your field
- rapid publication on acceptance
- support for research data, including large and complex data types
- gold Open Access which fosters wider collaboration and increased citations
- maximum visibility for your research: over $100 \mathrm{M}$ website views per year
At BMC, research is always in progress.
Learn more biomedcentral.com/submissions 